\title{
Repertórios organizacionais, relações pessoais e atuação profissional em partidos políticos ${ }^{1}$
}

Wilson José Ferreira de Oliveira²

\section{Resumo}

As análises sobre os partidos políticos têm sido dominadas pela investigação dos candidatos e eleitos. Contrariando essa tendência, este artigo focaliza os funcionários que ocupam cargos remunerados em diretórios de partidos políticos. A metodologia utilizada consistiu na realização de observação participante, questionários e entrevistas biográficas focando nas relações entre dinâmicas organizacionais, atributos sociais, relações pessoais e concepções de política vinculadas ao ingresso e à atuação profissional em partidos políticos. A pesquisa mostrou que variadas formas de relações pessoais constituem ingredientes fundamentais para o ingresso e a permanência em organizações partidárias, fazendo-se presente em todos os partidos pesquisados, independente das siglas e orientações ideológicas.

Palavras-Chaves: Etnografia Política; Relações Pessoais; Atuação Profissional; Partidos Políticos;

${ }^{1}$ A pesquisa que deu origem a este trabalho foi financiada pela CAPES, através do PROCAD NF 2009, pelo CNPq e Universidade Federal de Sergipe. Tipos de Financiamento: Auxílio para pagamento de serviços de terceiros, Bolsa de Iniciação Científica. Agradeço aos bolsistas Jonatha Vasconcelos Santos e Francisco Emanuel Silva Menezes Alves pela observação e redação dos diários de campo, pela aplicação dos questionários, realização de entrevistas e construção de banco de dados sobre os funcionários de partidos políticos de Sergipe.

${ }^{2}$ Doutor em Antropologia Social. Email: etnografia.politica@gmail.com 


\title{
O rganizational Repertories, Personal Ties and Professional Practices in Political Parties
}

\begin{abstract}
The analysis of political parties has been dominated by research about candidates and elected officials. Contrary to this trend, this article focuses on employees who occupy paid positions in management of political parties. The methodology consisted of participant observation, survey and biographical interviews focusing on the relations between organizational dynamics, social attributes, personal ties and political conceptions linked to the entry into and the professional practice within political parties. Research has shown that various forms of personal ties are very important for ingress and continuity in political parties, being present in all the political parties, regardless of acronyms and ideological orientations.
\end{abstract}

Keywords: Political Ethnography; Organizational Repertories; Personal Ties; Professional Practice; Political Parties;

A grande maioria dos trabalhos que trata direta ou indiretamente da política partidária, tem se voltado prioritariamente para a investigação da profissionalização política a partir de um tipo específico de profissional, qual seja: aqueles indivíduos que concorrem ou ocupam cargos eletivos (OFFERLÉ, 1999; CORADINI, 2001; GRILL, 2007; PERISSINOTTO, MIRÍADE, 2009; BOLOGNESI, 2013; GAXIE, 2012). Tal ênfase deixa de lado um conjunto de funcionários e profissionais que desempenha atividades fundamentais tanto para a conquista de cargos eletivos por parte dos candidatos quanto para a permanência e continuidade das próprias organizações partidárias. Desse modo, ela sugere, em muitos casos, certo descaso quanto à importância das dinâmicas concretas de organização e de funcionamento das organizações 
partidárias em benefício dos atributos, dos itinerários e dos êxitos de seus dirigentes.

Em consonância com isso estão, de um lado, os trabalhos que se centram nos chamados mecanismos institucionais, com ênfase no "problema da seleção de candidatos", buscando responder a questões como: "Quem pode ser eleito? Quem escolhe? Quem é selecionado? Quais as consequências do recrutamento?" (NORRIS, 2013, p. 11; BRAGA, BOLOGNESI, 2013). A preocupação aqui está centrada nas dinâmicas operacionais dos partidos políticos com base no exame de estatutos, normas internas e programas, valores culturais e normas sociais referentes aos candidatos apropriados, tipos de experiências e conhecimentos adequados, modelando a oferta de candidatos, oferecendo redes sociais, treinamentos, habilidades cívicas e experiência organizacional (NORRIS, 2013). Os resultados obtidos, em geral, estão quase sempre fundados em surveys e/ou entrevistas com candidatos ou eleitos. Nesse sentido, Bolognesi (2013) mostra, com base em survey com candidatos, como operam os partidos ao formarem a lista de candidatos a deputado federal, concluindo que, segundo eles tenham sido selecionados por filiados, delegados, líderes ou líder único, podemos demarcar nítidas diferenças entre eles quanto à estrutura e à dinâmica prática do processo de seleção de candidatos nas organizações partidárias.

De outro lado, estão os trabalhos que se centram nas propriedades e trajetórias dos candidatos ou eleitos, com base em informações biográficas diversificadas sobre eles. Trata-se, com isso, de apreender as propriedades sociais e os deslocamentos dos dirigentes partidários no espaço social e político e de articulá-las com mudanças e transformações diacrônicas (CORADINI, 2001; GRILL, 2008; MONTALVÃO, 2011; GAXIE, 2012; SEIDL; GRILL, 2013). Também nesse caso, é com base em informações e propriedades sociais dos candidatos e dos eleitos que são apreendidas as dinâmicas organizacionais dos partidos políticos, sua "modelagem organizacional" e a intersecção entre "expectativas organizacionais e experiências pessoais” (SAWICKI, SIMÉANT, 2011). 
Nesse sentido, pode-se dizer que, apesar das recorrentes oposições teóricas, metodológicas e institucionais entre os que se concentram nos chamados mecanismos institucionais e os que priorizam as características ou atributos sociais dos agentes, as dinâmicas e o cotidiano das organizações partidárias são mais pressupostas ou tomadas como dadas a partir das falas dos eleitos ou candidatos, do que efetivamente analisadas com base na observação dos atores diretamente envolvidos nos processos organizacionais colocados em prática pelos partidos em seus habitats naturais e em situações e contextos práticos (AUYERO, 2006; SCHATZ, 2009; OLIVEIRA, 2015). Pelo contrário, um aspecto comum ao conjunto dessas abordagens consiste justamente na tentativa de explicar repertórios e dinâmicas organizacionais (CLEMENS, 2009; 2010; SAWICIKI, SIMÉANT, 2011) com base em dados coletados por questionários e entrevistas aplicados a indivíduos (os candidatos e os eleitos) que têm uma posição particular na hierarquia do espaço social, político e partidário. Nesse sentido, pode-se dizer que no âmbito das organizações partidárias, como no da militância política, tudo indica que tais pesquisas têm aceitado como dado e evidente, o pressuposto da organização burocrática hierárquica, característico da tradição Michels-Weber (CLEMENS, MINKOF, 2009; CLEMENS, 2010).

Na contramão dessa recorrente ênfase dos estudos sobre a política a partir de candidatos e eleitos, em detrimento de investigações sobre dinâmica de funcionamento e de organização dos partidos políticos, a pesquisa que está na origem deste artigo teve como objetivo principal examinar as dinâmicas de seleção e inserção dos funcionários que ocupam cargos remunerados em diretórios nacionais, estaduais ou municipais de organizações partidárias. Assim, nosso objeto e problema de pesquisa estavam orientados para a investigação das condições e lógicas sociais que conduzem à ocupação de cargos remunerados em partidos políticos no estado de Sergipe. Sem a pretensão de atribuir previamente à realização da pesquisa certa exclu- 
sividade, seja dos atributos sociais e políticos dos funcionários dos partidos, seja dos mecanismos institucionais colocados em prática pelas organizações partidárias, tratou-se de examinar a importância das relações pessoais e o modo como se articulam às dinâmicas organizacionais e às concepções de política subjacentes ao ingresso e à atuação profissional deles em organizações político-partidárias.

Para dar conta de tais questões procedeu-se, primeiramente, ao levantamento dos diretórios estaduais dos vinte e oito partidos existentes no estado de Sergipe e dos nomes de seus principais dirigentes nos sites do Tribunal Regional Eleitoral e do Tribunal Superior Eleitoral. Com base nisso, num segundo momento, visitamos dezesseis diretórios onde realizamos observação direta, bem como aplicamos trinta e dois questionários com funcionários e dirigentes de dezenove, dos vinte partidos existentes em Sergipe: em seus diretórios, em suas residências, escritórios ou instituições de ensino onde eles estudam. Tais questionários tinham como eixos temáticos principais o levantamento de informações sobre suas origens sociais, os itinerários escolares e profissionais, os tipos de recursos e de vínculos sociais que fundamentam o exercício profissional e as principais modalidades de carreiras. Tal material possibilitou apreender os critérios de recrutamento para a ocupação de cargos dirigentes e empregatícios nessas instituições e traçar um perfil social dos que ocupam tais posições. No entanto, juntamente com os questionários, foram realizadas "entrevistas etnográficas" (BEAUD; WEBER, 1998) com funcionários dos diretórios municipais e estaduais. Elas foram feitas depois de um trabalho de observação em alguns partidos, enquanto, em outros, através de contatos já estabelecidos no processo de aplicação de questionário. Elas serviram para aprofundamento dos vínculos e relações que os conduziram ao referido cargo, assim como das concepções de sociedade e de política que fundamentam sua inserção e permanência nas organizações partidárias. 


\section{"Será que é só o PT que lhe recebe bem?"}

Foi com base na observação do cotidiano partidário que selecionamos e negociamos com os profissionais aos quais seriam aplicados os questionários e as entrevistas. Em alguns casos, o trabalho de observação foi impossibilitado devido a não autorização para realização do trabalho de campo. Todavia, foi através da incorporação de um "olhar reflexivo" sobre as observações dos diretórios e os contatos com os dirigentes, durante o processo de negociação e de aplicação dos questionários e de realização das entrevistas (BEAUD, WEBER, 1998; OLIVEIRA, 2015), que nos defrontamos com um conjunto relativamente novo de informações a respeito do funcionamento dos partidos políticos e que necessitavam consideração e explicação: formas de interação entre funcionários de diferentes partidos, dinâmicas de funcionamento organizacionais, redes de inter-reconhecimento entre partidos, etc. Desse modo, a inserção das diferentes técnicas utilizadas numa abordagem etnográfica e as informações encontradas nos colocou no desafio de, ao invés de partir de uma definição prévia de "partido político", tomá-la como uma categoria que está em jogo no próprio universo das organizações e das lideranças partidárias, fazendo parte da própria realidade que estamos investigando. Como bem adverte Bannani-Chraïbi (2000), tais informações não podem ser negligenciadas como matéria bruta ou anedótica, mas levadas a sério na medida em que são formas de "deixar falar o objeto" e que precisam ser seguidas para que possamos constituir, sob o concreto, os atores, os lugares e as temporalidades próprias do objeto (FAVRE, FILLIEULE, JOBARB, 2007).

Desse modo, nos repetidos encontros durante o processo de negociação da observação, da aplicação dos questionários e da realização das entrevistas observamos certa diferenciação quanto às formas de tratamento e de aceitação de nosso acesso aos partidos: de um lado, os que nos viam com certa desconfiança, e até mesmo com o que poderíamos inicialmente chamar de "medo"; 
de outro lado, os que se mostravam prontamente sem reservas e que nos acolhiam com solicitude.

0 tratamento sem reservas está associado a certo "conhecimento" ou contato prévio do entrevistado com as ciências sociais, com o coordenador da pesquisa, com o entrevistador ou mesmo com amigos e colegas de curso. Nesse sentido, encontram-se os partidos cujos entrevistados fazem ciências sociais e já tinham sido alunos do coordenador da pesquisa, colegas de curso do entrevistador ou amigos destes, bem como partidos nos quais, além dos aspectos anteriores, a presença de membros e militantes vinculados às ciências sociais é muito frequente (Partido dos Trabalhadores, PT; Partido Socialista dos Trabalhadores Unificado, PSTU; Partido Socialismo e Liberdade, PSOL; Partido Comunista do Brasil, PCdoB). Outra situação que facilitou o acesso e a disponibilidade dos entrevistados para a pesquisa foi o fato de ser "conterrâneo" do entrevistador. Tal situação facilitava o estabelecimento do contato, bem como certa descontração durante a conversa inicial, uma vez que dava acesso a acontecimentos, nomes de pessoas, lideranças e fatos políticos locais.

A atitude desconfiada, com reservas ou desinteressada, está associada às situações nas quais os entrevistados desconhecem o entrevistador, o coordenador da pesquisa e colegas do curso de ciências sociais ou, no máximo, quando demonstram certo conhecimento das ciências sociais e as vinculam a determinados partidos, como PT, PSOL ou PSTU. Uma situação ilustrativa disso foi um dos primeiros contatos com o diretório dos Democratas (DEM). Ao apresentar a pesquisa como vinculada à Universidade Federal de Sergipe (UFS) e com o tema dos partidos políticos, a atendente demonstrou certo medo e disse "que não tinha nada a ver com essas coisas", sugerindo falar com outro funcionário o qual indagou novamente quem era o entrevistador e sobre o objetivo da pesquisa. Situação semelhante ocorreu no Diretório Estadual do Partido Democrático Trabalhista (PDT), posto que uma senhora quando foi informada que o questionário visava 
coletar informações sobre funcionários dos partidos ficou assustada e apreensiva, dizendo imediatamente que não era funcionária. Situações semelhantes ocorreram no Partido Social Liberal (PSL), Partido Socialista Cristão (PSC), entre outros.

Essas diferenças quanto às formas de relacionamento com os pesquisadores e os objetivos da pesquisa, podem ser mais bem considerados quando se observa que as demandas por filiação que os entrevistados dirigiam aos pesquisadores não provinham de igual maneira do conjunto dos partidos contatados. Pelo contrário, no primeiro conjunto de partidos com os quais os pesquisadores tinham algum tipo de "proximidade" como descrito acima, isso nunca ocorreu. Em nenhum momento nos sentimos desconcertados e até mesmo constrangidos com indagações sobre em quem iríamos votar ou qual era nosso partido. No entanto, com os partidos com os quais tínhamos um maior "distanciamento" era muito comum sermos "presenteados" com adesivos, cartilhas, livretos e estatutos e com convites para filiação. Outras situações mais constrangedoras ocorriam quando no início da conversa, após expor os objetivos da pesquisa, ouvíamos o entrevistado nos perguntar se votaríamos em seu candidato.

Como se sabe, as dificuldades, os constrangimentos e as tensões que emergem do processo de inserção no terreno de análise, do levantamento das informações sobre o objeto e problema de pesquisa, assim como das formas de disponibilidade e de acesso aos entrevistados, a documentos, registros e práticas existentes, são "portadoras de uma informação positiva" sobre as condições e situações que as produzem, podendo "se converter em fontes de informação capaz de enriquecer nossa análise das formas da respectiva construção social" e ser consideradas como uma "realidade social a ser analisada como tal" (MERLLIÉ, 1996, p. 156-157). Por que certos contatos eram tão fáceis e amigáveis enquanto outros tão tensos e cheios de desconfiança? Por que em certos partidos éramos publicamente constrangidos a responder perguntas sobre nossas opções eleitorais enquanto que 
em outros partidos tais questões jamais vinham à tona? Até que ponto essas, e questões similares que surgiram em função do processo de pesquisa, já nos dizia algo sobre o modo de configuração da própria realidade social a ser investigada?

Aos poucos, e principalmente no caso daqueles partidos que se mostravam mais distantes e de difícil acesso, percebemos que o fato de ir ostensivamente a um mesmo diretório e o estabelecimento de conversas constantes sobre familiares, parentes e conhecidos, e mesmo sobre questões pessoais, possibilitaram a criação de uma relação de confiança com alguns funcionários e dirigentes de tais partidos. Isso facilitou o acesso à pesquisa e, em alguns casos, uma mudança da sensação inicial de desconfiança para uma atitude de maior descontração e solicitude.

Não é de hoje que se tem demonstrado o quanto o laço pessoal com pessoas que mantêm vínculos institucionais com o universo de pesquisa constitui um dos recursos principais para o acesso do pesquisador ao terreno de investigação. Tal como nas situações comuns ou no dia a dia do funcionamento institucional, elas têm um peso bem maior do que as "referências institucionais e formais": chamar a atenção para a "particularidade" de nossa situação, encontrar alguém que se faça de "porta-voz" de nossos interesses, utilizar argumentos e tratamentos pessoais, etc., constituem recursos bem mais eficazes para o ingresso e a obtenção de material relevante para a pesquisa, do que recorrer a obrigações e argumentos formais e institucionais (BEZERRA, 1995, p. 26-28).

No entanto, os pesquisadores, em geral, dão pouca importância à análise das condições sociais e dos processos de produção dos dados de sua pesquisa. Sem dúvida, um dos primeiros desafios que um olhar reflexivo sobre o objeto de análise nos colocou, consistiu justamente em levar a sério o próprio processo de aplicação de questionários e de realização de entrevistas e as respectivas informações que nos eram constantemente revela- 
das. Tal postura difere de uma prática que se tornou corriqueira na sociologia nos últimos anos, que consiste em elaborar uma espécie de lista das peculiaridades no percurso de determinada pesquisa e de suas relações com diferenças de posição social dos investigadores e investigados, no intuito de minimizar as dificuldades de acesso ao terreno e de transformá-las em "dados" (PINÇON; PINÇON-CHARLOT, 1991; CHAMBOREDON, 1994). Antes disso, ao invés de partir de uma problemática já pronta, nos sentimos desafiados a "seguir e deixar falar o objeto" partidos políticos, não apenas sobre o que interessava aos pesquisadores ou, no caso, as diferenças de posição social, mas sobre seu próprio estatuto, condições e formas de existência enquanto objeto.

Nesse sentido, tais situações nos colocaram em contato direto com os modos de operar dos partidos, com as concepções e práticas inculcadas pelos seus membros e funcionários, em suma, com relações constitutivas do universo que estávamos querendo pesquisar. Dito de maneira mais precisa, tais indagações, que surgiram das próprias observações e contatos iniciais com o universo da pesquisa, nos colocaram diante da importância dos laços, vínculos e relações "pessoais" como forma de acesso do pesquisador ao universo de pesquisa.

O estabelecimento de uma relação de confiança constitui um desafio e uma necessidade premente para o desenvolvimento de qualquer investigação (BEAUD; WEBER, 1998). Em consonância com isso, a partir do processo de aplicação de questionários a lideranças de partidos políticos, Bennani-Chraïb (2000) chamou atenção para a importância do trabalho, por vezes longo e paciente, de "confecção das redes de confiança". No nosso caso, a relação de confiança estabelecida durante o processo de negociação e realização das entrevistas somente foi possível pelo fato dos pesquisadores estarem previamente inseridos num universo próximo aos dos entrevistados e, até mesmo, manter "laços pessoais" com colegas, amigos e conhecidos destes. 
Tal aspecto está diretamente ligado às formas de entrada e de permanência dos funcionários nos partidos políticos. Ou seja, estamos diante de um universo social em que os "vínculos pessoais" estabelecidos com amigos, conhecidos ou políticos têm um forte peso para o ingresso e a permanência nas organizações partidárias. Nesse sentido, observamos que, em 28 questionários (dos 32 aplicados), um percentual de 78,60\% (atribui notas entre 3 e 5) reconhece a importância da indicação de amigos, conhecidos ou políticos na escolha do partido para o qual trabalha. Enquanto isso, os que consideram que tais tipos de vínculos tiveram pouca importância para o acesso ao cargo que ocupam no partido constituem um percentual de 21,4\% (atribui notas entre 0 e 2). De forma semelhante, o conhecimento prévio de colegas que eram da mesma área e atuavam já na instituição partidária também tem um peso relevante, de modo que os que atribuem notas de 3 a 5 alcança um percentual de 64,40\%.

Fatores que mais pesaram na escolha do partido para o qual trabalha - Indicação de algum amigo, conhecido ou político (Atribuição de nota de 0 a 5)

\begin{tabular}{|c|c|c|c|c|c|}
\hline & & Frequency & Percent & Valid Percent & Cumulative Percent \\
\hline Valid & 0 & 5 & 15,6 & 17,9 & 17,9 \\
& 1 & 1 & 3,1 & 3,6 & 21,4 \\
& 3 & 5 & 15,6 & 17,9 & 39,3 \\
& 4 & 3 & 9,4 & 10,7 & 50,0 \\
& 5 & 14 & 43,8 & 50,0 & 100,0 \\
& Total & 28 & 87,5 & 100,0 & \\
& System & 4 & 12,5 & & \\
& Total & 32 & 100,0 & & \\
\hline
\end{tabular}

Nesse sentido, mais do que uma simples dificuldade do processo de acesso ao terreno e ao material de investigação, tais observações e contatos estabelecidos anteriormente, bem como durante o processo de aplicação dos questionários e de realização das entrevistas, nos colocou diante de um dos aspectos mais constantes dos modos de operar dos partidos políticos e, particularmente, das formas de seleção dos que ocupam cargos remunerados em tais organizações, independente das siglas e ideologias 
partidárias: a importância dos "vínculos pessoais" com amigos, conhecidos, parentes, etc., para o ingresso em tais organizações.

Assim, tais situações demonstram que as negociações para o acesso ao terreno de investigação, com suas surpresas e inquietações, constituem situações privilegiadas para nos informar sobre as condições de produção tanto dos materiais e informações que poderão ser utilizadas como "dados" para a investigação quanto do próprio objeto de pesquisa. Por isso, a definição das técnicas de investigação não pode ser feita de antemão com base numa espécie de preferência teórica e metodológica prévia tanto a respeito do alcance e eficácia das "técnicas" quanto dos lugares, atores e temporalidades relacionadas aos objetos de investigação (BENNANI-CHRAÏB, 2000). Em nosso caso, a observação dos diretórios e a análise atenciosa dos eventos vinculados ao processo de negociação dos questionários e das entrevistas constituíram uma via para apreensão de uma série de aspectos constitutivos da dinâmica de organização dos partidos e das formas de atuação de seus funcionários e dirigentes.

\section{Repertórios 0 rganizacionais, Grupos Políticos e Alianças Partidárias}

O estabelecimento de vínculos pessoais e a confecção de redes de confiança não constituem os únicos aspectos que os partidos políticos expõem durante o processo de negociação do acesso às fontes de informação. Em muitos casos, o difícil acesso aos funcionários das organizações partidárias resulta da própria dinâmica de funcionamento do partido, no sentido de que muitos partidos não dispõem de infraestrutura e pessoal permanente para atendimento a um público mais geral.

Quanto a isso, uma dificuldade recorrente no trabalho de levantamento dos dados está diretamente ligada à própria dinâmica de funcionamento dos partidos e sua relação com o período 
eleitoral. Isso porque quanto mais próximo do período eleitoral, mais improvável de conseguirmos contatar os que trabalham nos partidos. Assim, em muitos casos, o difícil contato decorre do fato do funcionário estar totalmente envolvido com o processo de filiação daqueles que pretendem se candidatar a algum cargo eletivo no seu partido. Se as organizações partidárias constituem um dos fatores que contribui para que a política funcione como uma atividade permanente (WEBER, 1979; MICHELS, 1982; PHÉLIPPEAU, 2001), no caso em pauta, seu ritmo está diretamente dependente das temporalidades da política eleitoral, de modo que em muitos casos tanto o período imediatamente próximo às eleições quanto o muito distante constituem momentos de difícil acesso ao universo pesquisado: no primeiro caso, pelo excesso de atividades envolvendo os funcionários dos partidos; no segundo, pela inexistência de locais para atendimento e ausência de pessoal, uma vez que a organização somente dispõe de sede e pessoal permanente nos diretórios no período eleitoral. Desse modo, não foram poucos os casos em que não encontramos ninguém para atender ao telefone, tampouco os endereços que constavam no site do Tribunal Regional Eleitoral correspondiam à localização da sede. Cabe ainda salientar aqueles partidos cujas sedes, mesmo em períodos de maior agitação eleitoral, estão sempre fechadas e sem pessoas disponíveis para o atendimento.

No que concerne à existência ou não de funcionários com cargos remunerados em partidos políticos no estado de Sergipe, assim como no restante do Brasil, uma das condições importantes é o valor da arrecadação do partido no Fundo Partidário, administrado pelo Tribunal Superior Eleitoral (TSE). Uma das principais fontes de receita dos partidos políticos é justamente a oriunda do repasse das cotas do Fundo Partidário (Fundo Especial de Assistência Financeira aos Partidos Políticos), previsto no artigo 17, § $3^{\circ}$, da Constituição Federal, o qual é constituído pela arrecadação de multas eleitorais, doações de pessoas físicas ou jurídicas e dotações orçamentárias da União. 
Os recursos provenientes do Fundo Partidário devem ser aplicados na manutenção das sedes do partido, no pagamento de pessoal, na propaganda política, nas campanhas eleitorais, na criação e manutenção de instituto ou fundação de doutrinação e educação política e em programas de promoção e difusão da participação política das mulheres.

Em relação a isso, observa-se que $\mathbf{3 9 , 1 1} \%$ do total destinado aos partidos políticos no ano de $2013^{3}$ estão concentrados em apenas três partidos, no caso: PT com 16,09\%, PMDB com 12,01\% e PSDB com 11,01\%. Outro conjunto formado por cinco partidos têm uma participação de $\mathbf{3 1 , 4 1 \%}$ do total, no caso PR com 7,01\%, o PP com 6,72\%, o PSB com 6,68\%, o DEM com 5,01\% e o PSD com 3,66\%. Somados esses dois conjuntos pode-se dizer que oito partidos, do total de 32 , concentram 70,52\% do total destinado aos partidos políticos. Dos 24 partidos restantes encontramos um percentual de 22,94\% distribuídos em oito partidos, os quais contam com uma participação no fundo variando entre $1,82 \%$ a $4,74 \%$. Por fim, 16 partidos ficam com percentuais individuais abaixo de 1\% totalizando 6,54\% de participação do conjunto no fundo partidário.

Assim, a grande heterogeneidade e diferenciação em termos de estruturas e dinâmicas organizacionais que encontramos em nossas visitas às organizações partidárias parecem estreitamente ligadas às participações desiguais e diferenciadas dos partidos na distribuição do Fundo Partidário. Nesse sentido, um maior ou menor repasse de recursos do fundo a um determinado partido parece influir diretamente em questões capitais das estruturas partidárias como, por exemplo, manutenção de sedes, pagamento de funcionários, aquisição de equipamentos eletrônicos, etc. 
Em geral, o percentual das verbas provenientes do financiamento público constitui uma parte muito importante da estrutura das receitas dos partidos políticos (OFFERLÉ, 2012). Em Sergipe, a existência de funcionários com carga horária e funções específicas, ainda que diversificadas, apresenta-se, inicialmente, estreitamente ligada à participação do partido na arrecadação do Fundo Partidário. Nesse sentido, pode-se dizer que, se o processo de institucionalização dos partidos políticos tem sido marcado pela existência de quadros funcionais e/ou dirigentes detentores de competências específicas necessárias às suas atuações e que se dedicam a estas, a fim de atingir os objetivos de suas instituições, o percentual de participação do partido no fundo constitui um dos ingredientes importantes para que isso ocorra. Tal aspecto tem sido geralmente caracterizado, e também avaliado, como uma "crescente regulação estatal da vida partidária" no Brasil, à qual vem se aprofundando desde meados da década de 1990 (NICOLAU, 2010, p. 232). Nessa perspectiva, tem sido dito que esse processo tem contribuído para uma espécie de "estatização" dos partidos brasileiros, indicado pela crescente dependência destes em relação aos recursos estatais (fundo e horário partidário/eleitoral).

Todavia, essa relação entre a participação na arrecadação do Fundo Partidário e a constituição de uma estrutura organizacional e funcional não deve ser vista de forma mecânica ou mesmo automática, como se a existência e o número de funcionários dos partidos correspondessem de forma exata e proporcional ao percentual de participação no fundo. Um bom exemplo disso é o caso do Partido Socialista Brasileiro (PSB) em Sergipe que, mesmo figurando no ranking da arrecadação do fundo partidário em sexto lugar no ano de 2013, é o que possui o maior quadro funcional entre os partidos investigados, tendo quatro funcionários, enquanto que os demais têm apenas entre um e três. Tal observação é importante na medida em que nos coloca diante das condições de emergência e de consolidação dos partidos políticos e suas estreitas relações com a gênese e configu- 
ração dos principais grupos e lideranças dominantes no estado, com as relações de força e de colaboração existentes entre eles, bem como suas vinculações com as lógicas contextuais e locais de implantação das organizações partidárias e com o papel das alianças eleitorais na transformação das organizações e práticas partidárias (GOIRAND, 2007).

A respeito disso, observa-se que, em Sergipe, semelhante ao que se tem salientado a respeito do sistema político nacional, os partidos que apresentam uma maior participação na arrecadação do Fundo Partidário são justamente aqueles que estão mais diretamente ligados aos processos de afirmação e de diversificação dos principais grupos dominantes existentes no estado e ao estabelecimento de recorrentes alianças eleitorais entre eles (DANTAS, 2004). Desse modo, observa-se que em termos de siglas partidárias, a partir dos anos de 1980, a vida política do estado de Sergipe foi dominada inicialmente pelo PDS, depois pelo PFL (atual DEM) e pelo PSDB e, por fim, pelo PT a partir dos 2000 (primeiramente na capital em 2000 e no governo do estado, em aliança com o PMDB, a partir de 2006) (DANTAS, 2002). Em torno dessas siglas encontram-se alguns dos principais grupos políticos e lideranças dominantes no estado.

Primeiramente, o grupo liderado pelos Francos, que tem um papel destacado na política de Sergipe desde o governo militar, em torno da pessoa de Augusto do Prado Franco e que, atualmente, estão à frente do DEM e do PSDB que, inclusive, figuram hoje entre os partidos que têm uma participação relevante no fundo partidário (DANTAS, 2002). No caso do PSDB, trata-se de Albano Franco, um dos filhos de Augusto do Prado Franco, que governou Sergipe por duas vezes pelo PSDB (1995-1998; 1999-2002). No entanto, antes de entrar no PSDB ele transitou por vários partidos: na ARENA de 1966 até 1979, no PDS de 1980 a 1985, no PFL em 1985, no PMDB de 1986 a 1989 e no PRN de 1990 a 1992. No caso do DEM trata-se de João Alves Filho, um antigo aliado de Augusto do Prado Franco, que é atualmente presidente do par- 
tido e prefeito de Aracaju e que governou o estado de Sergipe durante três mandatos (1983-1986; 1991-1994 e 2003-2006). No caso do PSB trata-se de Antônio Carlos Valadares, vinculado inicialmente ao grupo liderado por Augusto do Prado Franco e, posteriormente, antigo aliado (vice-governador) e sucessor do então governador João Alves Filho como governador do estado (1987-1990).

Como representante de outra agremiação que tem uma posição destacada na arrecadação do fundo partidário, mas cuja história está vinculada à emergência e consolidação de grupos e lideranças políticas de Sergipe, que desde o governo militar eram do grupo oposicionista, destaca-se o PMDB (DANTAS, 2002; 2004). Atualmente, está sob a presidência do atual governador do estado, Jackson Barreto, que é uma liderança cuja carreira política remonta à década de 1970 na juventude do $\mathrm{MDB}$, tendo militado também no clandestino PCB. Por fim, o PT, cuja história também está associada à emergência de lideranças e grupos políticos inicialmente contrários ao governo militar. Sua ascensão no estado de Sergipe teve como uma das principais lideranças o ex-governador Marcelo Déda: deputado estadual de 1987 a 1990 e federal de 1995 a 1999 e de 2000 a 2001, quando foi eleito prefeito da capital do estado por dois mandatos sucessivos, até o ano de 2006, quando se licenciou do cargo para concorrer e assumir o governo estadual de 2007 a 2010, sendo reeleito e permanecendo no cargo até seu falecimento em 2014.

Como podemos ver, em Sergipe, semelhante ao que se tem salientado a respeito do sistema político nacional, os partidos que têm uma maior participação na arrecadação do fundo partidário são justamente aqueles que estão mais diretamente ligados aos processos de afirmação e de diversificação dos principais grupos e lideranças políticas dominantes no estado. Para isso, a configuração das alianças eleitorais, ainda que apresente forte variação segundo os estados da federação, tiveram um papel relevante, na medida em que contribuíram para o estabelecimen- 
to de relações de colaboração entre tais grupos, como também para a transformação das organizações e práticas partidárias (GOIRAND, 2007).

Assim, em meio à proliferação e a uma progressiva fragmentação do quadro partidário, em conformidade com as reformas da legislação partidária em âmbito nacional, e a uma relativa alternância dos principais partidos que governaram Sergipe a partir da transição democrática, a política estadual tem sido dominada até os anos 2000 pelos partidos vinculados a dois principais grupos: os franquistas (PDS, PSDB) e o grupo liderado por João Alves Filho (PDS, PFL, DEM). Evidentemente, isso não impedia que eles estabelecessem alianças em sucessivas eleições: nas para governador de 1990, 1994, 2006, 2010, 2014; nas para prefeito de 1992, 1996, 2000, 2012. No caso do PT que, a partir de início dos anos 2000, começa a ter uma implantação mais expressiva no estado, ocorre que até a eleição municipal de 1988 predominava uma estratégia de recusar alianças. No entanto, a partir da eleição para governador do estado de 1990 ele passou a estabelecer alianças com os partidos ideologicamente mais próximos. Na eleição de 2006 iniciou alianças com antigos aliados do PSDB e PFL; inclusive com o próprio PSDB na eleição para prefeito de 2008. Por fim, no caso do PMDB as alianças com os mais diferentes grupos e os partidos que têm maior sucesso eleitoral tem sido uma característica constante, independente das constantes mudanças das lideranças e grupos políticos sob a direção do partido (DANTAS, 2002): com o PFL (em 1985, 1988, 1990, 1994; 2000), com o PDS (em 1986; 1990), com o PSDB (em 1994; 1998; 2002), com o PT (em 2006, 2008, 2010, 2012, 2014).

Em linhas gerais, pode-se dizer que em Sergipe, entre 1985 e 2014, as alianças envolveram praticamente todos os partidos, independente do conteúdo ideológico das organizações. Isso não quer dizer que não tenha ocorrido diversificação dos grupos e lideranças políticas em concorrência, mas indica que isso 
teve como base certa continuidade dos principais grupos políticos que dominaram a política partidária e eleitoral no estado (DANTAS, 2002). Contribui para isso o fato da estruturação dessas alianças estar fortemente relacionada a práticas e estratégias partidárias individualizadas dos candidatos e de personalização da concorrência (DANTAS, 2002; GOIRAND, 2007). Tais formas de aliança consistem em investimentos voltados tanto para a consolidação quanto para a renovação de laços pessoais e políticos. Elas têm como base uma concepção de política fundada na distribuição de favores e no peso relativo dos partidos políticos na competição eleitoral, de modo que as práticas de representação são percebidas como resultado mais de "esforços e ações individuais" do que do "capital delegado" (Bezerra, 2013, p. 283). Essa importância das relações pessoais na dinâmica de funcionamento das organizações partidárias é um dos fatores constitutivos da continuidade de uma grande variação das "alianças, acordos, combinações e pactos entre diferentes partidos" no plano municipal, no estadual e no federal (QUEIROZ, 1976, p. 28-29).

\section{"Seguidores", "M ilitantes" e "Funcionários"}

Do mesmo modo que a procura pelos diretórios, a visita e observação deles, a aplicação do questionário e a realização das entrevistas nos colocam diante de um universo muito heterogêneo em termos das funções empregatícias exercidas nos partidos. A estrutura de funcionários contratados apresenta enorme variação de partido para partido: em alguns casos são recorrentes certas funções como secretário-geral, auxiliar administrativo, tesoureiro, enquanto que, em outros, tais atribuições são exercidas pelos próprios presidentes.

Por isso, se nossa pretensão, desde o início, era não limitar nossa investigação aos chamados "políticos profissionais", em algumas situações isso foi praticamente impossível. Desse modo, 
em nosso universo de entrevistados, $28,1 \%$ dos que exercem funções administrativas são dirigentes, não dispondo o partido de nenhum funcionário contratado. Encontramos também uma quantidade enorme de profissionais que atuam nos partidos, mas que são cedidos de outras instituições vinculadas à política do referido partido (21,9\%): funcionários públicos da prefeitura, da assembleia e do governo estadual, do senado federal, assessores parlamentares que prestam serviços ao partido, cargos de confiança, etc. Assim, apenas 37,5\% dos entrevistados são funcionários cujo vínculo com o partido é de efetivo contratado. Essa heterogeneidade quanto aos tipos de vínculos empregatícios com o partido se desdobra na combinação da função empregatícia exercida nele com outras funções na estrutura partidária e até mesmo em outras instituições. Quanto a isso, somente um percentual de $40 \%$ representa os que se dedicam exclusivamente ao exercício de funções empregatícias no partido, sem nenhum exercício de funções administrativas em outras instituições ou mesmo de direção na estrutura dirigente do partido. Já os dirigentes que desempenham funções empregatícias como funcionário, e que também fazem parte do quadro dirigente do partido, constituem um percentual de 43,4\%. Por fim, outro conjunto, que representa um percentual de $16,6 \%$, é formado por aqueles que se encontram na condição de cedidos ou licenciados, mas que exercem simultaneamente funções em outras instituições políticas e administrativas.

Tais diferenças de vínculos e de combinações de funções estão estreitamente vinculadas à posição do partido na distribuição do fundo partidário. Assim, aqueles partidos em que são recorrentes algumas funções como secretário-executivo, auxiliar administrativo, tesoureiro, etc., são justamente os que têm uma participação maior no fundo partidário, enquanto que são justamente os que dispõem de uma parcela muito pequena de tais recursos, aqueles nos quais é comum encontrarmos os dirigentes desempenhando ou acumulando estas funções com outras na estrutura dirigente do partido, bem como a utilização de pro- 
fissionais licenciados ou cedidos de outras instituições para desempenhar tais funções nos partidos. Todavia, em meio a essa enorme variedade em termos de estrutura organizacional, de vínculos e exercício de funções empregatícias nos partidos, o conjunto dos entrevistados apresenta algumas características gerais que merecem ser destacadas.

Trata-se de uma população com faixas etárias predominantemente acima dos 32 anos. Ou seja, apenas 18,8\% do total estão na faixa etária que fica entre 22 e 31 anos, enquanto que $68,7 \%$ estão na faixa que vai dos 32 aos 52 anos e 12,5\% estão acima de 52 anos. Dito de outro modo, destaca-se um percentual de 81,2\% de entrevistados que estão na faixa etária acima de 32 anos. Nesse sentido, pode-se dizer que não se trata de um conjunto cujo ingresso no partido é concomitante ou imediatamente posterior à entrada no mercado de trabalho, seja após a conclusão de seus estudos secundários ou mesmo universitário. Até mesmo porque dos 18 questionários que apresentam informações sobre o grau de escolarização, somente um percentual de 33,3\% possui formação universitária completa, enquanto que 55,6\% possuem apenas formação secundária completa. Antes disso, observa-se justamente que do total de 32 questionários um percentual de $87,5 \%$ exerceu atividades profissionais anteriormente à ocupação do atual cargo no partido, enquanto que apenas 12,5\% não exerceram atividades profissionais.

Desse modo, a forte articulação da formação escolar e universitária com a militância política não parece caracterizar a entrada no partido do conjunto investigado. Até mesmo porque, para o conjunto, a militância anterior em organizações estudantis, sindicais, religiosas, profissionais ou em associações de bairros e movimentos sociais é, em geral, muito pequena, não ultrapassando o percentual de $20 \%$. Pelo contrário, é muito alto o percentual dos que nunca participaram ou participam de movimentos sociais $(81,3 \%)$, organizações profissionais $(81,3 \%)$, associações de bairro $(78,1 \%)$, sindicatos $(75, \%)$, organizações 
estudantis (71,9\%). Mesmo a militância anterior em partidos políticos ou na própria organização em que trabalha é muito pequena, com um percentual de 12,5\%.

Isso não impede que, quando se trata da participação em partidos políticos, um percentual de 46,9\% diga respeito aos que tem nessa forma de organização seu primeiro engajamento político. Ao que tudo indica, isso ocorre porque tal engajamento e mesmo filiação é geralmente posterior ao ingresso no partido como funcionário e constitui uma forma de consolidação dos laços pessoais anteriormente estabelecidos com amigos, conhecidos ou políticos que os indicaram à ocupação do referido cargo. Como comprovação disso, está o percentual de $84,4 \%$ para os que são filiados ao partido em que integram o quadro funcional. Com base na definição de militância como atividade que diz respeito a "atores, que além do fato de se filiarem, desenvolvem ou ao menos desenvolveram um mínimo de participação em termos de atividades partidárias, seja enquanto militante de base, seja como liderança" (Rocha, 2009, p. 72), pode-se dizer que se trata de um universo de forte militância política. No entanto, mais do que algo que antecede o ingresso no partido, trata-se de algo que só se desenvolve e se consolida a partir do ingresso e da permanência na organização partidária.

Todavia, mais importante do que qualquer atributo em particular, e até mesmo de certa bagagem profissional e de militância anterior, são as relações pessoais que têm se apresentado como um fator essencial para o ingresso e o investimento nas organizações partidárias, corroborando achados de outros estudos sobre o tema que demonstram que a maioria deles constrói uma relação direta e pessoalizada com dirigentes locais do partido (GOIRAND, 2007; ROCHA, 2009). Ou seja, mesmo que certos atributos sociais se apresentem como características importantes para a dinâmica de entrada nos partidos, eles não aparecem como fatores essenciais ou mesmo determinantes para o ingresso e a permanência nos partidos. 
Pelo contrário, pode-se mesmo dizer que variadas formas de relações e de vínculos pessoais constituem ingredientes fundamentais para o ingresso e a permanência em organizações partidárias, fazendo-se presente em todos os partidos pesquisados, independente das siglas e orientações ideológicas. Assim, o ingresso na organização partidária resulta sempre desses vínculos e relações pessoais, mesmo que em alguns casos elas decorram de socialização em organizações, movimentos e grupos militantes (ROCHA, 2009). Tais formas de ingresso, fundamentalmente baseadas em vínculos pessoais com amigos, colegas e políticos, estão associados a concepções da atividade no partido como "boa gestão de relações pessoais e afetivas". Assim, em meio a um conjunto muito diversificado de posições e de cargos ocupados nos partidos políticos, os investimentos pessoais, políticos e profissionais dos funcionários nas organizações partidárias têm se apresentado sob a forma de três figuras principais: a do "seguidor", a do "militante" e a do "funcionário".

A figura do "seguidor" caracteriza-se por uma forte vinculação ao presidente do partido. Nessa situação, o vínculo pessoal de longa data com dirigentes do partido constitui a tônica principal, resultando em concepções que têm na relação de confiança a base principal da ocupação do cargo. Um exemplo bastante típico dessa forma de exercício de funções profissionais nos partidos é a de um técnico em contabilidade, licenciado do emprego de auxiliar administrativo, que exerce como cargo de confiança a função de secretário executivo do partido e atua nesta área há aproximadamente 35 anos. Ele é filho de comerciantes com baixa escolaridade por ele próprio definida como "alfabetizados", mas que não tinham engajamento político, embora tenha parentes que "já foram prefeitos". Mesmo que já tenha participado de movimentos sociais, seu primeiro engajamento foi em partido político, justamente em função do ingresso como técnico em contabilidade do partido. Todavia, seu ingresso nesse tipo de atividade teve como base suas amizades e a "necessidade". Pessoa de "confiança" do presidente do partido é a relação de 
"confiança" existente entre eles, desde longa data, aproximadamente 35 anos, que está na base da função que desempenha no partido, que o mantém no cargo e que o conduz à ocupação de tal função em diferentes cargos de vários partidos pelos quais já passou. Como ele mesmo relatou, "Na verdade eu sou o secretário dele", "Onde ele estiver ele me leva", "Trabalho com ele vai fazer 35 anos... Então pro partido que ele for eu vou". De forma recíproca o mesmo lhe disse: "Preciso de alguém para tomar conta do partido [...] Olhe! Você vai comigo". Dessa forma, ela já passou por todos os partidos que o presidente ingressou, tendo ocupado os cargos mais variados nas executivas destes, como: secretário do presidente do partido, assessor parlamentar especial, tesoureiro, etc.

Rapaz! 0 que me mantém no cargo é a confiança do presidente aqui dentro. Eu trabalho porque fico sempre disposto 24h. Na hora que ele liga, pode ser feriado, um sábado, um domingo à noite eu estou sempre... Agora mesmo eu estou começando a fazer a transmissão da televisão, então eu tenho que ficar ligado $24 \mathrm{~h}$.

A figura do "militante" toma alguns contornos diferenciados da do "seguidor" do chefe de partido. 0 principal deles é que, nesse caso, mesmo que os vínculos pessoais com dirigentes do partido constituam a base de seu ingresso e permanência no partido, tais vínculos resultam da inserção comum em organizações políticas e movimentos sociais, bem como estão fundadas em concepções de que a atuação política no interior do partido é um ingrediente importante do exercício de sua função. Como consequência disso, nessa forma de atuação profissional, o envolvimento com a "parte política" é bem maior do que o dos "seguidores". Um exemplo típico disso é o caso de um secretario executivo de diretório estadual que ocupa tal cargo desde 2006 e é formado em gestão em tecnologia da informação. Ele nasceu e morou todo o tempo no bairro América, que era um dos bairros da periferia de Aracaju e muito estigmatizado pela presença da violência e de drogas. Seu pai tinha ensino médio comple- 
to e era funcionário público, já sua mãe tinha ensino superior completo e era professora de um colégio privado, de modo que foi com base em seu vínculo de funcionária que conseguiu uma bolsa para o filho estudar lá. 0 fato de viver num bairro que era estigmatizado, a ponto de muitos vizinhos ter vergonha de dizer que morava nele, e estudar num colégio de classe média, o levou desde cedo a sentir certa discriminação por ser negro e morar em tal bairro. No entanto, foi somente quando iniciou o curso de engenharia química na Universidade Federal de Sergipe que, segundo ele próprio, teve a "a oportunidade de ficar mais à vontade" e iniciou o percurso que fez com que ele parasse em tal cargo. Isso porque foi nesse período que iniciou a militância no movimento estudantil e começou a trabalhar na iniciação científica com um professor que tinha sido presidente do DCE, depois foi pró-Reitor e, mais tarde, foi ser superintendente do IBAMA e presidente do partido. Foi pelo vínculo estabelecido com esse professor que ingressou no partido: primeiramente, como estagiário do IBAMA e, depois, como secretário do partido quando o mesmo tornou-se presidente do partido estadual. É com base nisso que ele afirma que foi "através da mão dele mesmo" que "vim parar aqui". Tal itinerário está associado a uma concepção militante do exercício do cargo que, para ele, funciona como uma espécie de "consultor" que ouve as angústias, os reclamos e os desabafos vivenciados nos municípios e faz a interlocução com as metas e as regras estabelecidas pela direção.

Porque eu sou, digo sempre, mais militante do que funcionário, eu acho que não tem como descasar as duas coisas. Até tem! Porque existem outras instituições que tem funcionários daqui e não tem uma relação militante, então eu sou militante que saiu lá do movimento estudantil, sou mais militante do que funcionário.

Por fim, na figura do "funcionário" tanto a relação com o chefe de partido quanto com a militância são bastante diferenciadas das demais. Nessa situação, ainda que os vínculos pes- 
soais constituam também o meio de ingresso no partido, ela não desemboca numa forte vinculação e até mesmo dependência em relação ao dirigente que o colocou no partido. Por outro lado, o distanciamento em relação à militância em organizações e movimentos sociais conduz a uma concepção do exercício do cargo no partido como uma função distanciada do envolvimento com ideologias, opções e atuações políticas. Um exemplo disso é o caso de um assessor político de diretório estadual que trabalha no partido desde 2003. Ele nasceu no Rio de Janeiro, mas sua mãe era de Aracaju. Aos três meses ficou órfão de mãe e foi, junto com a irmã, morar com a avó e o avô maternos em Aracaju. Seu avô materno era ex-combatente da marinha e após aposentar-se retornou a Aracaju. Durante sua formação escolar, nunca participou de grêmio estudantil e o que mais recorda como marcante do científico foi o gosto pela matemática que, segundo ele, teve um papel decisivo em sua formação. Em 2012 concluiu o curso de Tecnólogo em Gastronomia pela faculdade Serigy que, segundo ele próprio, "não tem nada a ver com partido político (risos)". No entanto, foi através de seu primo que era, e ainda é, um dos principais dirigentes do partido, que ingressou em tal cargo, em decorrência de ter surgido uma vaga. Todavia, isso não desembocou num maior envolvimento com a militância política e partidária. Pelo contrário, é certo distanciamento entre o que faz como funcionário e as exigências da política partidária que fundamenta o exercício de seu cargo.

Uma coisa é você ser funcionário e outra coisa é você ser político do meio, então uma coisa não tem nada a ver com a outra. Então talvez por isso o serviço flua melhor você não sendo político e você sendo técnico. Que tem pessoas que não sabem diferenciar. [...] Não sou militante, não sou político, minha amizade não é de político, minhas amizades não são de políticos, pode até ser que surja. Mas essas pessoas não são políticas, elas trabalham com política. [...] Não tenho amigo deputado, vereador, senador não são meus amigos 
Independente das legendas partidárias e dos grupos políticos vinculados às organizações partidárias, um aspecto recorrente na análise das formas de ingresso dos funcionários é que todos têm acesso a tal cargo a partir de laços e vínculos pessoais com dirigentes do partido, sejam laços diretos (com o próprio dirigente ou lideranças do partido), sejam indiretos (com parentes, amigos, colegas que têm vínculos mais fortes com determinado dirigente).

No entanto, apesar dessa linha de continuidade dos laços pessoais como forma de ingresso no partido, há uma clara diferença entre os funcionários quanto às concepções do exercício do cargo e de sua atuação nos partidos políticos. Assim, enquanto que para alguns o partido e o cargo resultam da manutenção e reafirmação de fortes vínculos estabelecidos com determinado dirigente, para outros tal atuação se combina com uma intensificação do engajamento e da militância política anterior que, como eles próprios dizem, são essenciais para se manter e continuar exercendo suas funções nos partidos, já para outros sua atuação não ultrapassa a agenda profissional de entrega de documentos para abertura de campanha, ou qualquer outra função, e ocorre mediante certo distanciamento das atividades e atuação político-partidária.

Uma via pertinente para o desafio de tentar entender a estruturação e constante redefinição de tais comportamentos consiste em mergulhar nas dinâmicas locais e nos repertórios organizacionais dos partidos políticos e em suas relações com os diferentes grupos e lideranças políticas em concorrência nos diferentes planos do funcionamento partidário (municipal, estadual e federal), assim como a forma como tais relações vão se consolidando e se configurando no transcurso do tempo. Em relação a isso, cabe apenas mencionar que tais desafios ainda estão muito distantes da agenda de pesquisa sobre os partidos políticos. 


\section{Conclusões}

Não é de hoje que a falta de interesse em descobrir a "racionalidade" e a "linha de continuidade" internas da política brasileira tem sido apontada como responsável pelas análises que a veem como "caótica", "absurda" e "irracional" (Queiroz, 1976, p. 29). Nos últimos anos tem persistido, e até mesmo se expandido tal atitude, apesar da grande renovação e diversificação teórica, conceitual e metodológica dos estudos sobre os fenômenos políticos no Brasil. Semelhante ao que tem acontecido em outras áreas de investigação, contribui, para isso, a persistência na produção acadêmica nacional de certa tendência de importação, utilização e "difusão de abordagens conceituais, de problemáticas e de interpretações homogêneas", com base na inserção e circulação de estudantes e pesquisadores entre grupos e redes de pesquisa vinculadas a universidades e instituições dos EUA e da Europa, colaborando, assim, para que os esforços de teorização continuem parciais e limitados (GOIRAND, 2010, p. 460; OLIVEIRA, 2013). "Coladas como etiquetas" aos fenômenos políticos (QUEIROZ, 1976, p. 18) muitas das ideias, conceitos e resultados vinculados a tais abordagens acabam sendo utilizados com um "viés claramente normativo", na medida em que atribui um estatuto negativo ou secundário às relações pessoais no "ordenamento das relações sociais", interpretando-as como "sobrevivência de relações tradicionais" ou, na melhor das hipóteses, como "indício de desenvolvimento incompleto" das instituições políticas (BEZERRA, 2013, p. 284).

No âmbito dos estudos dos partidos políticos, isso está associado à tendência de concentração dos estudos no exame dos indivíduos que concorrem ou são escolhidos para a ocupação de cargos eletivos. Tal viés expressa, em certa medida, uma dificuldade muito presente de acesso ao universo dos partidos políticos e de suas dinâmicas concretas de organização e funcionamento. Em contraponto a isso, a pesquisa que está na base deste artigo foi orientada pela tentativa de dar conta de um tipo de profis- 
sional que é quase sempre mencionado nos trabalhos (os burocratas do partido, os auxiliares de candidatos e eleitos), mas que tem recebido pouca atenção da literatura sobre os partidos. Dessa forma, este artigo procurou ampliar o olhar sobre as organizações partidárias com base no exame da "constituição dos diferentes tipos de atores que compõem um coletivo" e do curso mesmo de suas ações e intervenções (CEFAÏ; TROM, 2001, p. 18), ao invés de considerá-las com base apenas nos indivíduos que tiveram êxito no processo eleitoral.

Um "olhar reflexivo" sobre o processo de negociação do trabalho de campo e a utilização das diferentes técnicas com base numa abordagem etnográfica nos colocaram diante da importância dos vínculos pessoais com amigos, conhecidos, parentes, etc. para o ingresso e a permanência dos funcionários em tais organizações. Antes de nos defrontarmos com uma dificuldade que é apenas "metodológica" de adequação da técnica ao universo da pesquisa, estávamos diante de um dos aspectos mais constantes das formas de ingresso e de seleção dos funcionários de tais organizações, independente das siglas e ideologias partidárias.

Sem dúvida, há uma enorme heterogeneidade e variação dos partidos políticos em termos organizacionais em decorrência da posição do partido na distribuição do fundo partidário. Todavia, tal índice de participação na arrecadação do fundo partidário está em estreita relação com os processos de afirmação e de diversificação dos principais grupos e lideranças políticas dominantes no estado. Nesse sentido, a estruturação das alianças eleitorais fundadas em práticas e estratégias partidárias "individualizadas" dos candidatos e de "personalização" da concorrência, contribui para minimizar as distâncias entre os partidos em termos de infraestrutura e de pessoal, possibilitando a consolidação de certas organizações partidárias, assim como a renovação dos laços pessoais e políticos entre tais grupos e lideranças. 
No âmbito das formas de ingresso, de acesso e de permanência dos funcionários nos cargos das organizações partidárias, uma das principais linhas de continuidade diz respeito também à importância dos laços e vínculos pessoais com dirigentes do partido, sejam laços diretos, sejam indiretos. Ao mesmo tempo, apesar da recorrência de tais laços, pode-se identificar diferentes concepções dos funcionários quanto ao exercício do cargo e sua atuação nos partidos políticos, o que se expressa de forma mais detalhada através da descrição do itinerário e das formas de atuação de três figuras principais: a do "seguidor", a do "militante" e a do "funcionário".

Tais resultados confirmam a importância de se considerar de forma relacional as condições e lógicas burocráticas, os laços e vínculos pessoais, assim como suas combinações com diferentes recursos sociais e formas de atuação profissional. Tal perspectiva constitui um dos principais ingredientes para a ruptura com as abordagens normativas e negativas dos partidos políticos no Brasil e para escaparmos da armadilha que consiste em considerar os dados em comparação com "um modelo político ideal" e que acaba por adjetivar a política brasileira com termos como "Mandonismo", “Coronelismo", "Patrimonialismo" e "Clientelismo". Com base nisso, passamos a lidar com múltiplas configurações históricas de combinação entre dinâmicas organizacionais, atributos e laços pessoais e concepções de política partidária. Para isso, é fundamental a adoção de uma sensibilidade que esteja voltada para a apreensão dos significados que as pessoas estudadas atribuem à sua realidade social e política, assim como a tarefa de tomar como objeto de análise a própria existência dos agregados como: Estado, partidos, movimentos, etc. (AUYERO, 2006; SCHATZ, 2009; LATOUR, 2007). 


\section{Referências}

AUYERO, Javier. Introductory Note to Politics under the Microscope: Special Issue on Political Ethnography, Qualitative Sociology, vol. 29, n 3, 2006, pp.; 257-9.

BEAUD, S. \& WEBER, F. Guide de l'Enquête de Terrain. Paris, La Découverte, 1998.

BENNANI-CHRAÏBI, Mounia. Quand négocier l'ouverture du terrain c'est déjà enquêter. Obtenir la passation de questionnaires aux congressistes de partis marocains. Revue internationale de politique comparée, 2010/4 Vol. 17, pp. 93-108. DOI : $10.3917 /$ ripc.174.0093

BEZERRA, Marcos O. Representantes Políticos, Relações Pessoais e Reputação. In: SEIDL, Ernesto; GRILL, Igor G. As Ciências Sociais e os Espaços da Política no Brasil. Rio de Janeiro, FVG, 2013, pp. 279-318.

BEZERRA, Marcos O. Corrupção: um estudo sobre poder público e relações pessoais no Brasil. Rio de Janeiro, Relume-Dumará/ANPOCS, 1995.

BOLOGNESI, Bruno. A Seleção de Candidaturas no DEM, PMDB, PSDB e PT nas Eleições Legislativas Federais Brasileiras de 2010. Percepções dos candidatos sobre a formação das listas. In.: Revista de Sociologia e Política, Curitiba, v. 21., n 46, pp. 45-68, jun 2013.

BRAGA, Maria do Socorro S.; BOLOGNESI, Bruno.Dossiê Recrutamento Político e Seleção de Candidatos nas Democracias Contemporâneas. In.: Revista de Sociologia e Política, Curitiba, v. 21., n 46, pp. 5-9, jun 2013.

CHAMBOREDON, Hélène. et al. S'imposer aux imposants; A propos de quelques obstacles rencontrés par des sociologues débutants dans la pratique et l'usage de l'entretien. In: Genèses, 16, juin, 1994. pp. 114-132.

CLEMENS, Elisabeth S. Repertórios organizacionais e mudança institucional: grupos de mulheres e a transformação da política nos EUA, 1890-1920. In: Revista Brasileira de Ciência Política, no 3. Brasília, janeiro-julho de 2010, pp. 161-218.

CLEMENS, Elisabeth S.; MINKOFF, Debra. Beyond the Iron law: Rethinking the place of organizations in social movement reserach. In: SNOW, David A.; SOULE, Sarah A.; KRIESE, Hanspeter (eds.). The Blackwell Companion to Social Movements (Blackwell Companions to Sociology). Oxford, Blackwell Publishing, 2009, pp. 155-170.

CORADINI, Odaci L. Em Nome de Quem? Recursos Sociais no Recrutamento de Elites Políticas. 1a.. ed. Rio de Janeiro: Relume Dumará/UFRJ, 2001 
DANTAS, José I. C. História de Sergipe República (1889-2000). Rio de Janeiro, Tempo Brasileiro, 2004.

DANTAS, José I. C. Eleições em Sergipe (1985-2000). Rio de Janeiro, Tempo Brasileiro, 2002.

FAVRE, Pierre, FILliEUle, Olivier et JOBARB, Fabien. L'Atelier du Politiste. Théories, actions, réprésentations. Paris, La Découverte/PACTE, 2007.

GAXIE, Daniel. As Lógicas do Recrutamento Político. In.: Revista Brasileira de Ciência Política, no8. Brasília, maio - agosto de 2012, pp. 165-208.

GOIRAND, Camille. Pratique Partisanes et Loi Électorale au Brésil. In.: DABENE, Olivier (ed.). Amérique Latine, les élections contre la démocratie?. Paris: Presses de Sciences Po, 2007, pp. 41-77.

Penser Les Mouvements Sociaux d'Amérique Latine. Les approches des mobilisations depuis les anneés 1970. Paris, Revue Française de Science Politique, vol. 60, no 3, 2010, pp. 445-466.

GRILL, Igor G. Elites, Profissionais e Lideranças Políticas (RS e MA): pesquisas recentes. São Luís, EDUFMA, 2008.

LATOUR, Bruno. Jamais Fomos Modernos. Ensaio de Antropologia Simétrica. Rio de Janeiro, Editora 34, 1994.

MERLLIÉ, Dominque. A Construção Estatística. In: CAMPAGNE, Patrick. et al. Iniciação à Prática Sociológica. Petrópolis: Vozes, 1996, p. 107-170.

MICHELS, Robert. Sociologia dos Partidos Políticos. Trad. de Arthur Caudon. Brasília, EDUnB, 1982, 243p.

MONTALVÃO, Arivaldo T. Recrutamento de Elites Parlamentares em Sergipe: os deputados da ARENA (1965-1979). 2011. Dissertação (Mestrado em Sociologia) - Programa de Pós-Graduação em Sociologia, UFS, São Cristóvão, 2011.

MONTALVÃO, Arivaldo T.; SEIDL, Ernesto. Arena Sergipana: Trajetórias Políticas dos Deputados Federais. São Cristóvão, Scientia Plena, Vol 6, № , 3, 2010.

NICOLAU, Jairo. "Partidos e Sistemas Partidários (1985-2009)". In: LESSA, Renato (Coord. de área). In: Horizontes das Ciências Sociais Brasileiras: Ciência Política. São Paulo: ANPOCS, 2010. 402p. (pp.217-240)

NORRIS, Pippa. Recrutamento Político. In.: Revista de Sociologia e Política, Curitiba, v. 21., n 46, p. 11-32, jun 2013.

OFFERLÉ, Michel. "Professions et profession politique." In: OFFERLÉ, Michel (org.). La profession politique (XIXe-XXe siècles). Paris: Éditions Belin, pp. 07-35, 1999. 
OLIVEIRA, Wilson José F. de. Antropologia, Política e Etnografia: entre fronteiras disciplinares e problemas empíricos (no prelo). In: PERISSINOTTO, R. M., CODATO, A. Metodologia do Estudo de Elites.

PERISSINOTTO, R. M., MIRÍADE, A. Caminhos para o Parlamento: Candidatos e Eleitos nas Eleições para Deputado Federal em 2006. DADOS - Revista de Ciências Sociais, Rio de Janeiro, Vol. 52, no 2, pp. 301-333, 2009.

PHÉLIPPEAU, E. "Sociogênese da profissão política”. In: GARRIGOU, A. \& LACROIX, B. Norbert Elias: a política e a história. SP: Perspectiva, 2001.

PINÇON, Michele; PINÇON-CHARLOT, Monique. Pratiques d'enquêtes dans l'aristocracie et la grande bourgeoisie. Genèses, 3, mars, 1991. pp. 120-133.

QUEIROZ, Maria Isaura P. O Mandonismo Local na Vida Política Brasileira e outros ensaios. São Paulo, Alfa-Ômega, 1976.

ROCHA, Daniela. Militantismo Partidário e Experiência de Poder. 0 caso do PT no Distrito Federal. In: Antropolítica, Niterói, EdUFF, 2009, pp. 67-95.

SAWICKI, Frédéric; SIMÉANT, Johanna. Inventário da sociologia do engajamento militante. Nota crítica sobre algumas tendências recentes dos trabalhos franceses. Sociologias, Porto Alegre, ano 13, no 28, set./dez. 2011, pp. 200255.

SAWICKI, Frédéric. Les Réseaux du Parti Socialiste. Sociologie d'un milieu partisan. Paris, Belin, 1997.

SEIDL, Ernesto; GRILL, Igor G. As Ciências Sociais e os Espaços da Política no Brasil. Rio de Janeiro, FVG, 2013.

SCHATZ, Edward. (Ed.). Political Ethnography. What immersion contributes to the study of power. Chicago, Universty of Chicago Press, 2009.

WEBER, M. A Política Como Vocação. In.: Ensaios de Sociologia. Rio de Janeiro, Guanabara, 1979, pp. 97-153.

Recebido em 15/12/2015

Aprovado em 30/12/2015 